\title{
The Defense Life Cycle Management System As A Working Model For Academic Application
}

Philip E. Burian, Colorado Technical University - Sioux Falls, USA

Leslie M. Keffel, Colorado Technical University - Colorado Springs, USA

Francis R. Maffei III, Colorado Technical University- Online, USA

\begin{abstract}
Performing the review and assessment of masters' level degree programs can be an overwhelming and challenging endeavor. Getting organized and mapping out the entire review and assessment process can be extremely helpful and more importantly provide a path for successfully accomplishing the review and assessment of the entire program. This paper will provide a roadmap that was used as a guide for accomplishing a successful review and assessment of academic degree programs in a logical and succinct manner by adapting a proven model originally developed for the acquisition and life cycle management of new equipment, materials, and systems. This paper will also discuss how the Integrated Defense Acquisition, Technology, and Logistics Life Cycle Management System process was adapted to the needs of an academic institution of higher-learning.
\end{abstract}

Keywords: program assessment; assessment roadmap; process; model; academic process model; defense acquisition university; PLM

\section{INTRODUCTION}

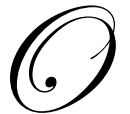

$\mathrm{n}$ the national level, the Integrated Defense Acquisition, Technology, and Logistics Life Cycle Management System (ILC) is the cornerstone of the federal government's acquisition and life cycle management for acquiring new equipment, materials, and systems. The Program Managers Toolkit (April, 2009) describes the ILC as a pictorial roadmap of the key activities in the system acquisition process. Donald Rumsfeld, former Secretary of Defense, addressed a way of thinking that needed to be apply for the future - "As we prepare for the future, we must think differently... We must transform not only the capabilities at our disposal, but also the way we think, the way we train." (DAU Performance Learning Roadmap, 2005, pg. 1)

At Colorado Technical University (CTU) the University's Management Program Committee (UMPC) had a dilemma. The Master's degree programs were scheduled for a content revision and course level assessment. Initially, the task did not sound unreasonable or overly difficult to accomplish. Adding to the complexity of the review process was the diverse locations of the ground campuses (Colorado, Missouri, and South Dakota) and the online division (Illinois). The program committee researched numerous academic and professional journals and periodicals and was not able to find an effectively implemented model that provided a process for completing the academic review, revision, and assessment process. A number of the committee members had prior military or federal government service experience and suggested consideration of the ILC as a possible procedural model for the review process. This practice-based paper addresses the application and implementation of the Defense Acquisition, Technology, and Logistics Life Cycle Management System (ILC) at one academic institution of higher learning. 
The committee also considered the tenets of Kerzner's (2009) 16 points to Project Management Maturity, specifically the following points:

1. Adopt a project management methodology and use it consistently.

2. Implement a philosophy that drives the company toward project management maturity and communicate it to everyone.

3. Minimizes scope changes by committing to realistic objectives.

4. $\quad$ Focus on deliverables rather than resources.

5. Share recognition for project success with the entire project team and line management.

6. Eliminate non-productive meetings

7. Focus on identifying and solving problems early, quickly, and cost effectively.

8. Measure progress periodically.

Kerzner's (2009) points were extremely effective in cutting to the heart of the task to include the review, revision, and assessment of the university's Master of Business Administration (MBA) core course set and providing the UMPC with a clear focus as the committee progressed.

The committee members were all well aware that the ILC as a model is focused on system level acquisitions, but believed with adjustments to the processes and steps the ILC could be successfully implemented in an academic setting for master's level content and course review assessment. The UMPC goal was to apply and implement program level management to a process that in the past and supported by research has been left to the ideas and thoughts of the academic community. The committee believed the application of a defined process model could enhance the academic assessment process practices and steps that had not been implemented with uniformity in the past. To understand the depth and breadth of the dilemma the reader needs to know the quantity and diversity of the master's degree programs. The assessment review was to encompass $11 \mathrm{MBA}$ degree programs and 1 Executive MBA (EMBA) degree program and 46 individual courses.

The transition of a widely accepted system acquisition model for application in an academic environment at first appeared to be a stretch, but after further analysis and review the ILC was determined to be a very detailed and thorough process model that could be adapted to an academic environment. The ILC is time tested, has been validated by the Department of Defense and is widely accepted as the premier system acquisition model. The task for the UMPC was to use the tenets and objectives addressed in the ILC and tailor the components for an academic environment. To understand how to modify the ILC model for an academic environment starts with understanding the key milestones and phases of the Integrated Defense Acquisition, Technology, and Logistics Life Cycle Management System model.

\section{PROCESS FRAMEWORK}

A review of the Integrated Defense Acquisition, Technology, and Logistics Life Cycle Management System literature identifies that the key milestones, phase specific criteria, and stator requirements. The guide for the transformation was the Integrated Defense Acquisition, Technology, and Logistics Life Cycle Management System wall chart version 5.3.4 dated June 2009. The wall chart identified 5 major phases and 4 milestones for the system acquisition process. To understand what was accomplished the initial step for the committee was to collect the definitions that correspond to the milestones and phases.

\section{Integrated Defense Acquisition, Technology, And Logistics Life Cycle Management System}

A variety of Defense Acquisition University (DAU) publications provided an overall view of the system acquisition process. These resources can provide structure and a depth of understanding for the philosophical orientation of research approaches and the methodologies. Of course, there are many publications that address the system acquisition process and in some situations are specific to an acquisition type. The first task was to review the milestones and the corresponding phases as identified on the ILC wall chart. 
MDD - Materiel Development Decision, the Milestone Decision Authority may authorize entry into the acquisition process at any point, consistent with phase-specific entrance criteria and statutory requirements.

Materiel Solution Analysis Phase - Complete Analysis of Alternatives to assess potential materiel solutions to capability need, identify key technologies and estimate life cycle costs. Consider commercial-off-the-shelf and solutions from both large and small business. Identify materiel solution to capability need. Complete Technology Development Strategy.

MS A - Milestone A decision point for transition to Technology Development Phase from Materiel Solution Analysis Phase.

Technology Development Phase - Reduce technology risk, determine and mature appropriate set of technologies to integrate into full system, demonstrate critical technology elements on prototypes, and complete preliminary design. Identify an affordable program or increment of militarily useful capability, demonstrate technology in relevant environment, and identify and assess manufacturing risks. Provide for two or more competing teams producing prototypes of system and/or key system elements prior to or through Milestone B.

MS B - Milestone B decision point for transition to Engineering \& Manufacturing Development Phase from Technology Development Phase

Engineering \& Manufacturing Development Phase - Develop a system or increment of capability; complete full system integration, develop affordable and executable manufacturing process; ensure operational supportability; reduce logistics footprint; implement human systems integration; design for production; ensure affordability; protect critical program information; and demonstrate system integration, interoperability, safety, and utility.

MS C - Milestone $\mathbf{C}$ decision point for transition to Production \& Deployment Phase and finally to Operations \& Support Phase from Engineering \& Manufacturing Development Phase

Production \& Deployment Phase - Achieve operational capability that satisfies mission needs. Low-rate initial production (limited deployment for software intensive systems with no development hardware) and full-rate production (full deployment for software intensive systems). Deliver fully funded quantity of systems and supporting material and services for program or increment to users.

Operations \& Support Phase - Execute support program that meets materiel readiness and operational support performance requirements and sustains system in most cost-effective manner. Overlaps Production and Deployment Phase.

The final process step identified in the ILC wall chart is "Disposal" which would constitute the re-initiation of the Integrated Defense Acquisition, Technology, and Logistics Life Cycle Management System for a new system acquisition.

\section{UNIVERSITY MANAGEMENT PROGRAM COMMITTEE (UMPC) TASKING}

The direction for the committee's tasking was straightforward and succinct. The tasking included:

- $\quad$ Review the courses, sequence and content of the MBA core courses, MBA concentration courses, and the EMBA to assess their need, viability, content, and currency in today's business marketplace.

- Identify a common MBA core of courses that can be implemented for all MBA degree programs.

- $\quad$ Ensure implementation of the Colorado Technical University's Professional Learning Model (CTU PLM тм). The CTU PLM тм places students in the active role of collaborative problem solvers and project initiators confronted with the task of producing a deliverable that mirrors a real-world context and assessment. 
- $\quad$ Provide a consolidated report of the course and degree program level needs to include if courses or degree programs need to be removed from the active rolls due to small student population, low evaluations, or outdated degree programs.

In practice the CTU PLM TM places students in the active role of collaborative problem solvers and project initiators confronted with the task of producing a deliverable that mirrors a real-world context and assessment. Why is the PLM approach so successful? Recent research (Folley, pg. 99) has found:

- $\quad$ "the scope of the lecture can be broadened by using 'active learning' strategies and encouraging students to engage more interactively with lecture material, with the lecturer and each other in the lecture theatre."

- $\quad$ "since individual needs differ, there is no reason why a single learning or teaching technique will work equally well for everyone"

The Folley research (Folley, 2009) also supported prior research by David Leasure, PhD., (Leasure, 2004) that had shown students can achieve knowledge and skills much more rapidly and effectively if:

- $\quad$ Students have a high status in the learning environment

- The learning environment is engaging

- $\quad$ Concepts are immediately connected to real-world and personal experiences

- $\quad$ Students engage in realistic projects

- $\quad$ The subject matter is of immediate value

- $\quad$ The instructor and student should engage in an active dialog

The committee also reviewed the DAU Performance Learning Model (PLM). The DAU PLM provides a network-centric learning environment that overcomes the barriers of time, location, and distance, while delivering learning assets with speed, agility, and reach. (DAU Performance Learning Roadmap, 2005, pg. 5). The objectives of the DAU PLM were very helpful and provided the UMPC will additional insight to boundary-less learning. The DAU objectives include:

- $\quad$ Deliver a network-centric learning enterprise with just-in-time learning and knowledge-sharing assets

- $\quad$ Combine the best of classroom training with Web-based instruction, providing scalability and expanding the anytime, anywhere advantage

- $\quad$ Provide a new mix of learning opportunities directed at making smart business decisions.

The University Management Program Committee was able to blend the DAU PLM with the CTU PLM TM objectives to design and develop degree programs that would provide the engaged learner with a life-long learning opportunity. Although the UPMC tasking only included 4 tasks, the 12 degree programs and 46 individual courses made the review and assessment effort daunting. To complicate the process the 46 courses encompassed 11 different academic disciplines or knowledge areas. Collecting the subject matter experts in one location was a challenge, so having an assessment process with well defined steps and milestones become paramount to the committee's overall success.

\section{CONCEPTUAL FRAMEWORK OF THE UMPC}

The committee's baseline for the transition of the Integrated Defense Acquisition, Technology, and Logistics Life Cycle Management System was the wall chart which identified the key milestones and phases. The academic version of the ILC was titled the Academic Assessment Life Cycle Management System (AALCMS).

\section{Academic Assessment Life Cycle Management System}

These ILC resources provided the committee with the needed structure, concepts, and methodologies for focusing the AALCMS. The next step was the remaking of the milestones and phases to display a more academic 
focus. Listed are the AALCMS milestones and phases implemented by the UMPC for course/program level review and assessment. Figure one illustrates the functional flow of the process used by the UMPC.

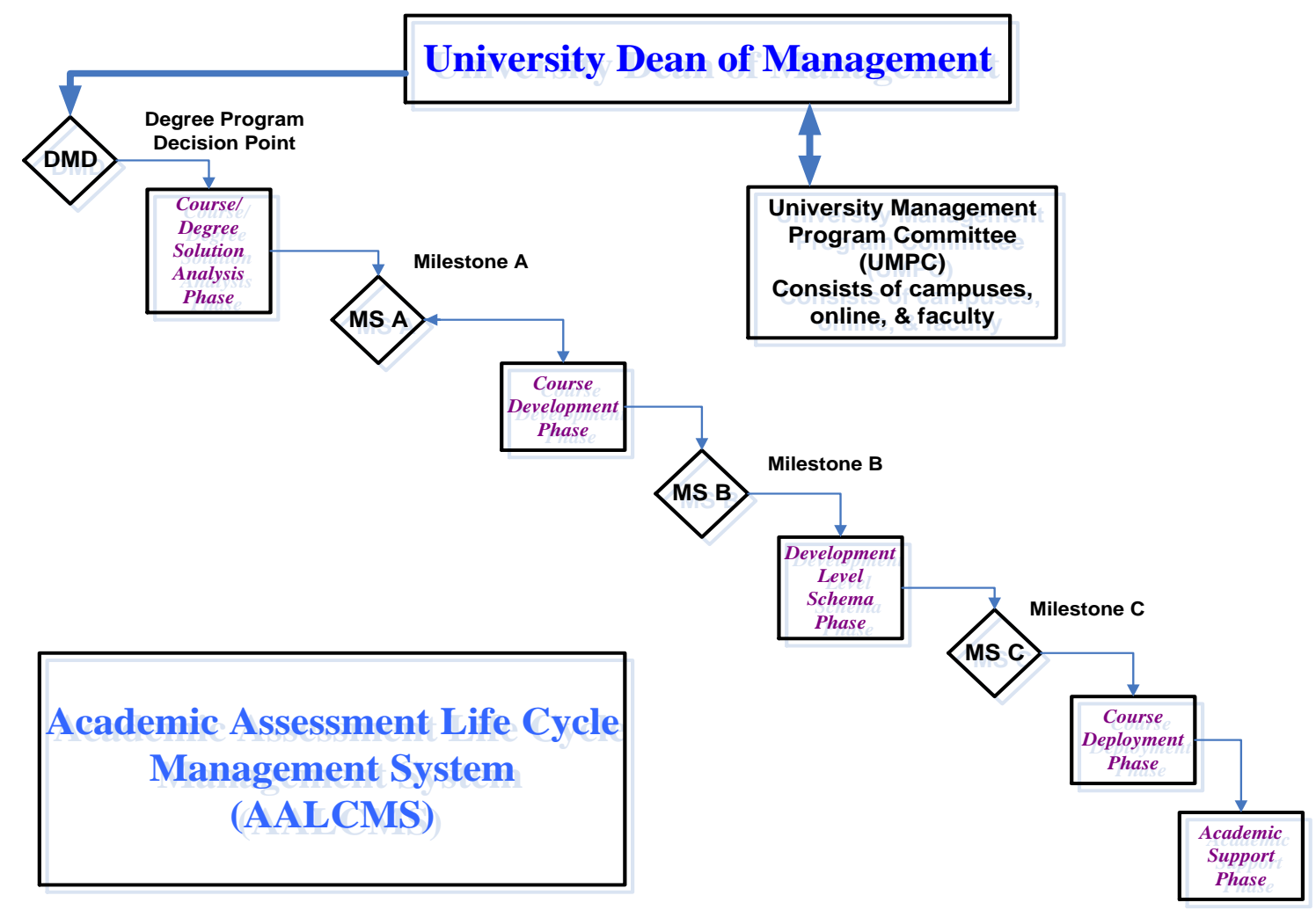

Figure 1: AALCMS Functional Process Flow

DPD - Degree Program Decision a primary decision point for the University Dean for Management as the Decision Authority may authorize entry into the review, revision and assessment process at any point, consistent with phase-specific entrance criteria and statutory requirements. The Dean was evaluating the initial review and assessment of which courses and/or master's level degree programs would require more work than others.

Course/Degree Solution Analysis Phase - Complete Analysis of Alternatives to assess potential solutions to capability needs, identify key competencies to be achieved, and an estimate of development costs. Consider commercial-off-the-shelf and solutions from publishing sources and other universities (for example Harvard Business Case Studies).

MS A - Milestone A decision point for transition to Course Development Phase from Course/Degree Solution Analysis Phase.

Course Development Phase - Reduce risk, determine and mature appropriate set of professional association competencies to integrate into course and appropriate degree program, demonstrate new course development application elements on prototypes, and complete prototype design. Identify an affordable program or useful capability, demonstrate in a relevant virtual or campus environment, and identify and assess potential risks.

MS B - Milestone B decision point for transition to Development Level Schema Phase from Course Development Phase 
Development Level Schema Phase - Develop a systematic course level integration, ensure operational supportability, implement human systems integration, ensure affordability, and demonstrate full system integration, interoperability, safety, and utility. To protect the development structure, faculty, and students the implementation will be in a controlled test bed with only one cohort of students attending the revised courses to minimizes problems and focus on the results.

MS C - Milestone C decision point for transition to Course Deployment Phase and finally Academic Support Phase from Development Level Schema Phase. The University Dean of Management was responsible for approving the transition to Milestone C.

Course Deployment Phase - Achieve operational capability that satisfies the professional competency, review, revision and assessment needs. Initially a limited deployment of new courses with revised presentation and formatting. CTU Course Development will phase in over a 3-6 month period fully developed courses and supporting material and services for the degree program.

Academic Support Phase - Execute support program that meets the university's operational and academic support performance requirements and will sustain curriculum in most cost-effective manner. This phase will overlap with Course Deployment Phase.

At this point the review, revision, and assessment process would start again with a new system requirement and acquisition need.

\section{ACADEMIC ASSESSMENT LIFE CYCLE MANAGEMENT SYSTEM (AALCMS) PROCESS RESULTS}

\section{DPD - Degree Program Decision}

The first step of the review and assessment process was to identify the MBA core courses, extract copies of the courses, tasks, and identify the associated professional competencies. The inventory of the MBA core courses identified 16 courses that were directly associated with the degree program topic title - MBA Core Courses. As a point of reference the Colorado Technical University MBA core courses were only 7-8 courses. By recognizing the sequence of the various courses the committee was able to identify gaps in knowledge and logic structures. For example, a student having taken finance and economics courses prior to attending a statistics course. Sequencing was the primary component of the initial analysis performed prior to the Degree Program Decision. The sequencing of courses within a degree program became as important as the analysis of the courses themselves. The University Dean of Management was the decision authority for transition from DPD to other milestones or continuation of pre DPD analysis.

From the review and assessment of the MBA degree programs and specifically the large number of MBA identified core courses and the identified course sequencing gap analysis the University Dean of Management approved the UPMC to move forward with the Course/Degree Solution Analysis Phase of the MBA Core degree program.

\section{Course/Degree Solution Analysis Phase}

The committee solicited comments, ideas, and information from senior management, adjunct faculty, course developers as well as any interested parties. Simultaneously to collecting comments and ideas the committee performed an external research of competitor master's degree programs to build a foundation of information and potential alternatives. The researched competitors were from North America as well as overseas academic institutions. To understand the possible solution the committee wanted as much information and data as possible that could assist with making a best decision possible.

\section{MS A - Milestone A}

The University Dean of Management, after review of the research information and the inventory and sequence results provided by the UPMC, approved the transition to Course Development Phase activities. 
Course Development Phase - This phase was the committee's detailed analysis of what would be the potential workload to build a succinct and clear set of MBA core courses, which courses would require review and re-working of the terminal course objectives and task list, and which courses did not achieve an acceptable level of CTU PLM activity. The end result of this phase was an inventory of all MBA core courses currently identified, the courses sequencing, and an assessment of the revision workload priority. To simplify the process of determining a revision workload the priority scale ranged from categories 1 to 3 based on a number of revision workload activities:

- $\quad$ priority 1 - minor work, for example typographic corrections, new textbook, activities that could be resolved in 2 days or less, basic PLM principles were achieved,

- $\quad$ priority 2 - revision work by the subject matter expert that would require some revision of terminal objectives, some task revisions, 2-5 days of work, basic PLM principles were not achieved or were weak and course material will need to be revised,

- $\quad$ priority 3 - major revisions to the course to include rewriting of the learning objectives, revising the task lists, new textbook, and 5-14 days of revision work. PLM principles were not achieved, were weak, missing and course material revision would be accomplished as the course is completely revised.

- In some situations a new course was required to be developed from the ground up, making the process more workload intensive, for example a new course from learning objective development to a finished and published course could 2-4 months of work by the subject matter expert, the course design project developer, the audio/video staff, and finally the pre-publication review process.

To better understand the gaps and learning objectives of the courses they were compared to MBA program objectives. This simple analysis was accomplished to identify gaps in the courses as compared to the program objectives. The gap analysis identified which current MBA core courses complimented the program objectives and which courses had no barring of program objectives.

The analysis of the course sequence identified some significant gaps in knowledge, learning, skills attained, and lack of uniformity among MBA degree programs. The course sequence was not as affected by the program objectives as were the courses themselves. The committee believed once the core courses were identified and agreed upon the sequencing could be accomplished rather effectively.

The final step of the phase process was to recommend the $8 \mathrm{MBA}$ core courses that would be implemented for each of the $11 \mathrm{MBA}$ degree programs. The 8 course topic areas selected were: accounting, finance, economics, statistics, leadership and ethical decision-making, marketing, research methods, and business strategy. In addition each MBA degree would have 3 emphasis or concentration courses for a total of 11 MBA courses for the curriculum. Of the 8 course topic areas selected five were a priority 1 , one was a priority 2 , and two were new courses.

\section{MS B - Milestone B}

The University Dean of Management reviewed all of the course and degree information and supporting materials and will either approve or hold-back the committee from moving forward to Development Level Schema Phase.

Development Level Schema Phase - The UPMC was able to consolidate, filter, and to identify by course what level of revision work needed to be accomplished. The results of the review and assessment was 10 of the 16 courses were priority 1, 4 courses were Priority 2, 2 courses were Priority 3. Additionally, 2 new courses were identified as being required, one course was a blending of Leadership and Ethical Decision-making and the other was a completely new course in research methods.

A budget and risk analysis was accomplished by the finance office to determine the workload capability of the course development division and the timeline for completion. To facilitate the work loading of the subject matter experts, course development staff, and to correspond to the yearly academic schedule a decision was made to work simultaneously on the priority 1 courses and the 2 new courses and then to start the priority 2 and 3 courses once the priority 1 course revisions were completed and published. The committee believed the priority 1 courses could be 
accomplished the quickest and provides the most effective change/revision management. The 5 priority 1 courses that were designated for the new MBA core course set were accomplished ahead of other priority 1 courses and the same was true with the priority 2 MBA core course.

The final process was the sequencing of the MBA core course set. Table 1 depicts the MBA core courses set in sequence order and the required foundation or refresher courses identified.

Table 1: MBA Core Course Sequence

\begin{tabular}{|l|l|}
\hline Leadership and Ethical Decision-making & Accounting foundation course if required \\
\hline Accounting & \\
\hline Research Methods & Statistics foundation course if required \\
\hline Statistics & \\
\hline Marketing & Finance foundation course if required \\
\hline Finance & \\
\hline Concentration Course 1 & Economics foundation course if required \\
\hline Economics & \\
\hline Concentration Course 2 & \\
\hline Concentration Course 3 & \\
\hline Strategy & \\
\hline
\end{tabular}

\section{MS C - Milestone C}

The University Dean of Management reviewed all of the course revision work accomplished along with the supporting information and supporting materials. The course revisions were focused on the implementation of the CTU PLM TM principles. The MBA core course program was approved for transition to the Course Deployment and Academic Support Phases.

Course Deployment Phase - The priority 1 courses were implemented within a calendar quarter of their review and revision. The course development staff was able to quickly implement the revisions and to adapt the audio and video materials to support the revisions. The first priority was to complete the priority 1 and 2 revisions of the MBA core course set. To complicate the process the sequence of courses started with one of the new courses, although a blending of leadership and ethical decision-making the full roll-out of the new MBA core course set was delayed approximately one quarter until at least 6 of the 8 core courses were ready for full implementation.

Academic Support Phase - Once the MBA core course set was populated and the university catalog had been amended to reflect the changes to the core courses set, the core course set were placed into operational use and support. Once a course completes deployment and is populated in the curriculum the course is then maintained by subject matter experts based on changing business conditions, feedback from faculty, or feedback from students.

\section{CONCLUSIONS}

At the national level, the Integrated Defense Acquisition, Technology, and Logistics Life Cycle Management System (ILC) is the cornerstone of the federal government's acquisition and life cycle management of new equipment, materials, and systems. Like any successful model, ILC is so strong in foundation that with creativity and innovation a model can be successfully adapted to applications outside the conventional federal government application.

The end result of the ILC adaptation, and implementation was Colorado Technical University's 12 MBA degree programs all have the same core course set and sequenced to maximize student learning and knowledge. The DAU PLM and CTU PLM ${ }^{\mathrm{TM}}$ objectives and principles were critical to the effective redesign of the masters' degree programs. The benefits of the UPMC review and assessment are seen in the lack of complexity of student enrollment activities, student advising, and student completions. By following a process model the committee was able to implement a logical, succinct, and comprehensive series of steps to accomplish the task at hand. 
This paper has demonstrated that the ILC can be effectively tailored and implemented outside the normal parameters for which the Integrated Defense Acquisition, Technology, and Logistics Life Cycle Management System was designed. However, further research and perhaps tailoring needs to be accomplished to determine if this model is repeatable and sustainable in an academic environment.

\section{AUTHOR INFORMATION}

Philip E. Burian, D.M. is currently the Dean of Business and Management at Colorado Technical University in Sioux Falls, South Dakota. Dr. Burian has been with Colorado Technical University since 1998 in various rolls from adjunct faculty to Program Chair. He received his doctorate in 1998 from Colorado Technical University in Management. Dr. Burian has over 30 years of experience in the military and with industry in various leadership positions from startup to Fortune 500 companies. He holds a MA degree in Management as well as a BS in Electronics and Technology.

Les Keffel, Ph.D. is currently Director of General Education and High School Partnerships for Colorado Technical University - Southern Colorado. Dr. Keffel joined CTU in the Department of Business and Management in 1999 holding various positions on the faculty and administration. He served 25 years in the U. S. Air Force and has over twenty years of experience in education and education administration. Dr. Keffel received his Ph.D. from the Josef Korbel School of International Studies, University of Denver, in Comparative International Politics and Policy Analysis in 1993 and also holds a BS in Education and an MA in Management and Public Administration.

Francis R Maffei III, D.M. is currently the Program Director for Business and Management at Colorado Technical University's Online Division. Dr. Maffei has been with Colorado Technical University since 1998 in various roles from adjunct faculty to Program Chair and Program Director. He received his doctorate in 1997 from Colorado Technical University in Management and is a graduate of Defense Acquisition University's Program Manager Course. Dr Maffei has over 20 years of experience in the military in various leadership and management related positions. He holds a MS degree in Logistics Management as well as a BS in Industrial Management.

\section{REFERENCES}

1. Bahnmair, Bill and Cochrane, Chuck. (June 2009). Integrated Defense Acquisition, Technology, and Logistics Life Cycle Management System. Version 5.3.4. Defense Acquisition University Fort Belvoir, Virginia.

2. Folley, Duncan. (2009). The Lecture is Dead Long Live the e-lecture. Electronic Journal of e-Learning http://www.ejel.org/volume-8/v8-i2/v8-i2-art-5-htm.

3. Kerzner, Harold PhD. (2009). Project Management: A Systems Approach to Planning Scheduling, and Controlling. $10^{\text {th }}$ Edition. John Wiley and Sons, Inc. Hoboken, New Jersey.

4. Leasure, David PhD. (2004). Teaching and Learning with CTU's Professional Learning Model (CTU $\mathrm{PLM}^{\mathrm{TM}}$ ). Computer Science Technical Report Number CTU-CS-2004-001. Colorado Technical University. Colorado Springs Colorado.

5. Project Management Institute (PMI). (2008). A guide to the Project Management Body of Knowledge (4 ${ }^{\text {th }}$ Edition). Newton Square, PA.

6. Defense Acquisition University (DAU). (2005). Performance Learning Roadmap. Fort Belvoir, Virginia.

7. Defense Acquisition University (DAU) (April 2009). Program Manager's Tool Kit (15 ${ }^{\text {th }}$ Edition). Fort Belvoir, Virginia. 
NOTES 